Bangladesh J. Plant Taxon. 26(2): 249-257, 2019 (December)

(C) 2019 Bangladesh Association of Plant Taxonomists

\title{
MORPHO-MOLECULAR CHARACTERIZATION OF CERATOBASIDIUM SP.: A MYCORRHIZAL FUNGI ISOLATED FROM A RARE EPIPHYTIC ORCHID GASTROCHILUS CALCEOLARIS (J. E. SM.) D. DON
}

\author{
Mohammad Musharof Hossain \\ Department of Botany, University of Chittagong, Chittagong 4331, Bangladesh
}

Keywords: Orchid mycorrhiza; ITS sequencing; Gastrochilus calceolaris; Ceratobasidium.

\begin{abstract}
A mycorrhizal fungus, Ceratobasidium sp. GC (NCBI Gene Bank Accession no GQ369961) associated with the roots of an epiphytic orchid Gastrochilus calceolaris was investigated by cultural morphology, microscopic features and molecular analysis of Internal Transcribed Spacer (ITS) regions sequences of nuclear ribosomal DNA. The colony appearance of the fungal endophyte was fluffy growth pattern and the colour of the young colony was milky white on both surfaces that turned in to brown at maturity on the upper surface and deep brown on reverse surface. The microscopic features of the fungus i.e. hyphal diameter, multi-nucleate vegetative cells, right angle branching pattern with slight constriction at branching point and a dolipore septum near the branching point were observed. All the characters corroborated the identity with anamorphic Rhizoctonia like fungi. The ITS regions sequences of nrDNA and phylogenetic analysis based on the neighbor-joining method showed clustered with Rhizoctonia like fungi, and the maximum identity (98.28\%) with Ceratobasidium RR and Ceratobasidium FPUB isolated from Rhynchostylis retusa and Dactylorrhiza hetagera, respectively. Thus, the ITS of nrDNA sequences validated the morphological data. This is the first report of orchid mycorrhizal fungi from Bangladesh.
\end{abstract}

\section{Introduction}

Mycorrhizal fungi are fundamental in orchid growth and metabolism, and influence the distribution and rarity of these delicate plants. The existence of mycorrhizal associations has been established since long in orchids with certain heterogeneous groups of fungi (Hadley, 1982). It is a biotrophic mutualistic symbiosis prevalent in more then $90 \%$ of the higher plants in which both partners benefited in terms of nutrients exchange, evolution and fitness. It is one of the most significant events in the successful colonization of land by plants and the evolution of biotrophic root-inhabiting symbioses. Now-a-day, it is the most interesting area of research throughout the globe. Seed germination in orchids is totally dependent on mycobionts due to lack of sufficient food reserves (Smith and Read, 1997). Orchids are categorized as myco-heterotropic, holomycotropic and mixotropic based on their nutritional dependency on fungal partner (Dearnaley, 2007). The orchids which depend on mycorrhizal fungi during seed germination stages only are referred as mycoheterotropic. The achlorophyllous orchids entirely depend on mycorrhizal fungi for nourishment throughout their life cycle are categorized as holomycotropic. The third orchid nutritional mode exists mixotrophy. Such orchids are photosynthetic at the adult stage but augment their nutrition requirements specially carbon via mycorrhizal fungi (Dearnaley, 2007). Mixotrophic orchids may be an evolutionary step between autotrophic and mycoheterotropic orchids (Julou et al., 2005). Nevertheless, all orchids are mycoheterotrophic during their early stages of growth, development and survival in nature. Mycorrhizal fungi

*Corresponding author: Email: musharof20bd@yahoo.com 
colonizing roots of terrestrial orchids were well investigated for their beneficial effects on seed germination, growth and ecological fitness of the host plants (Currah et al., 1987; Bidartondo, 2005). Only limited information is available for mycorrhizal fungi in epiphytic orchids which constitute a majority of orchids (Pereira et al., 2003). Therefore, isolation and identification of mycobionts is of interest for understanding orchid-fungus relationship in epiphytic orchids.

From the foundation work of orchid mycorrhiza, Rhizoctonia spp. was considered to be the only fungal partner associated with orchids. Afterward a number of fungi identified from orchids which showed resemblance to anamorphic Rhizoctonia spp. in many aspects, hence are collectively called Rhizoctonia-like fungi (Ramsay et al., 1987; Andersen and Staplers, 1994, Andersen, 1996; Shan et al., 2002, Sharon et al., 2008). The Rhizoctonia species associated with orchids include free-living saprophytes (Burgeff, 1959) and opportunistic soil pathogens. Thus, it is essential to establish the true biological entity of the mycobionts.

Conventionally the Rhizoctonia-like fungi are characterized based on the cultural morphology, cytomorphology of the hyphae, development of asexual resistant propagule i.e. monilioid cells, number of nuclei in the cells, branching pattern, nature of septum, anatosmosis group (AG) etc. (Shan et al., 2002). The conventional approaches for identifying orchid mycorrhizal fungi have some limitations as the majority of fungal partners are mycelia sterilia necessitating application of molecular techniques for their accurate identification (Shan et al., 2002; Dearnaley, 2007; Yagame et al., 2008). Fungal molecular systematics have been instrumental for the identification of orchid mycorrhizal symbionts because it overcomes the limits associated with in vitro isolation and morphological characterization of orchid endophytes. The aim of this study was to characterize morphologically and molecularly of the mycorrhizal fungi Ceratobasidium sp. GC isolated from Gastrochilus calceolaris and to test the coincidences between morphological and molecular characterization which will facilitate to isolate and accurate identification of mycorrhizal fungi in other orchids as well.

\section{Materials and Methods}

Sample preparation and isolation of fungal endophyte

Roots of Gastrochilus calceolaris (J. E. Sm.) D. Don were collected from the naturally grown plants from Bandarban district of Chittagong Hill Tracts, Bangladesh $\left(21^{\circ} 11^{\prime}\right.$ and $22^{\circ} 22^{\prime} \mathrm{N}$ latitudes and $92^{\circ} 04^{\prime}$ and $92^{\circ} 41^{\prime} \mathrm{E}$ longitudes; 300 - $500 \mathrm{~m}$ amsl) in June-July (rainy season) and November-December (winter season) were used for isolation of fungal symbionts. Three roots sampled from five plants were studied for estimating the percentage of cells with fungal colonization. Several transverse sections were cut at different portions of the roots attached to the tree trunk. Five thin sections taken randomly from each root were stained with lactophenol triglycero-cotton blue and observed for colonization under Labophot microscope (Nikon Corp., Japan). The incidence of fungal colonization and formation of pelotons in the root sections was calculated by following formula:

Number of cells colonized 20x microscope field view

Total number of cells 20x microscope field view

The root portions showing presence of fungal pelotons were surface sterilized in $4 \%$ sodium hypochlorite for $3 \mathrm{~min}$, dipped in $70 \%$ ethanol for $1 \mathrm{~min}$, and washed thoroughly with double sterile distilled water. The root sections $1.0-1.5 \mathrm{~mm}$ thick were aseptically transferred onto potato 
dextrose agar (PDA) supplemented with $0.75 \mu \mathrm{g} / \mathrm{ml}$ streptomycin sulfate and incubated in dark at $25{ }^{\circ} \mathrm{C}$ until hyphal growth was started from explants onto the medium. The fungal endophytes those started growing from the cortex cells of the root section were considered to be putative mycorrhizal fungi. Pure cultures were obtained by successive sub-culturing of small portion of the fungal mat from the fast growing zone to fresh PDA.

Study of cultural characteristics of fungal endophyte

Colony surface and reverse colours were recorded at young and mature stages. The hyphal diameter was measured in lactophenol triglycero-cotton blue mounts on glass slides under Nikon E600 microscope (Nikon Corp., Japan). Culture growth rates were determined by inoculating uniform mycelium bits at the centre of PDA plates and measuring radial increments in colony size at $48 \mathrm{~h}$ interval over two weeks in three replications.

\section{Study of microscopic features of fungal endophyte}

Nuclei number in vegetative cells was determined using slightly modified method of Shan et al. (2002). A small portion of the mycelial mat was fixed in $2 \%$ formaldehyde for 2 min on a glass-slide and rinsed with distilled water for $1 \mathrm{~min}$, followed by staining with Gold antifade reagent with diamidino-2-phenylindole (DAPI, ProLong®, Invitrogen Ltd., Eugene, OR, UK) for $10 \mathrm{~min}$, de-stained with distilled water for $2 \mathrm{~min}$, and observed using $50 \%$ glycerol under Nikon E600 microscope equipped with fluorescence mode.

\section{Isolation of DNA and PCR amplification}

For extraction of DNA 1g mycelial mat from 7 days old cultures was ground under liquid nitrogen using Qiagen DNeasy Plant Kit according to the instruction provided by the manufacturer (Qiagen, CA). The amplification of ITS 1, 5.8S rRNA gene and ITS 2 was achieved using the ITS1 (5'TCCGTAGGTGAACCTGCGG) and ITS4 (5'GCTGCGTTCA TCGATGC) primers (White et al., 1990). The PCR reaction was performed in $50 \mu \mathrm{l}$ reaction mixture containing $50 \mathrm{ng}$ genomic DNA, 10 pmol of each primer, $0.5 \mathrm{mM}$ of dNTPs, $1 \times$ PCR buffer with $1.5 \mathrm{mM} \mathrm{MgCl}_{2}$, and $3 \mathrm{U}$ Taq polymerase. The thermocycling conditions consisted of an initial denaturation at $94^{\circ} \mathrm{C}$ for $2 \mathrm{~min}$, followed by 35 amplification cycles at $94^{\circ} \mathrm{C}$ for $1 \mathrm{~min}, 54^{\circ} \mathrm{C}$ for $1 \mathrm{~min}$ and $72^{\circ} \mathrm{C}$ for $2 \mathrm{~min}$, and a final extension at $72^{\circ} \mathrm{C}$ for $8 \mathrm{~min}$. The sequencing of PCR product was done by ABI Prism Big Dye Terminator v. 3.1 Cycle Sequencing Kit (Applied Biosystem, CA, USA).

\section{Phylogenetic analysis}

The sequences were analyzed using the gapped BLASTn http://www.ncbi.nlm.nih.gov search algorithm and phylogenetic tree was constructed using the TREECON software package using Kimura's two-parameter model (Kimura, 1980) after aligning the sequences with CLUSTAL W version 1.83 (Thompson et al., 1994). The ITS region sequences ( 600 bp) of the fungal isolate were deposited in the NCBI GenBank database under the accession numbers GQ369961 for Ceratobasidium sp. strain GC (http://www.ncbi.nlm.nih.gov/btast).

\section{Results and Discussion}

\section{Fungal infestation in roots}

The fungal endophytes showed colonization in the cortex cells with peloton formation in the mature roots of the orchid (Fig. 1A). Colonization was observed only in the root portions attached with the substratum but no pelotons were found in the root tips. Colonization was absent the in aerial roots. In the colonized roots the pelotons were appeared as loose coils surrounded by live hyphae in the outer-cortex while brownish in the inner cortex. The frequency of root colonization 
was significantly higher $(75 \%)$ in June-July than November-December $(50 \%)(\mathrm{CD}=1.02$ at $p=0.05$ ). Seasonal variation in fungal infestation with higher colonization during the summer and rainy season of active growth and flowering as compared to the winter season of slow growth corroborated the earlier reports of higher colonization by fungi to meet the nutrient requirement for active growth and phenology of the orchids (Masuhara and Kutsuya, 1994; Siddique and Raghuvanshi, 1993; Chang, 2007).

Fungal hyphae were penetrated through root hair and passed through epidermis to the cortex and proliferated in the middle and inner layers of the cortex, forming pelotons in the cortical region of host's roots. Both young and mature pelotons were found in the root's cortex cells. Connections between the pelotons in the adjacent cortical cells through the cell wall were observed (Fig. 1A), which is a typical orchid mycorrhizal feature (Thakur et al., 2018). It was also observed that hyphae did not penetrate to the endodermis and pith. Initially pelotons showed loosely coiled hyphae in the cortex cells (the 'host' phase), followed by the hyphae collapsing into the centre of the cell (the 'digestive' phase, Thakur et al., 2018).

\section{Morphological characterization of fungal endophyte}

Morphological features of the fungus isolated from the roots of G. calceolaris showed resemblance to the Rhizoctonia-like orchid endophytes. The young colonies were cottony white that turned into light brown on upper surface and deep brown on reverse at maturity (Fig. 1B, C and D). A slight constriction at branching point and a dolipore septum was observed near the branching point of the new hypha (Fig. 1E). Microscopic features of the fungal endophyte are summarized in table 1 . The vegetative cells of this endophyte were multinucleate (Fig. 1F) without monilioid cells were observed during the course of study even the cultures were kept for one month in growth chamber. Conventionally, Rhizoctonia-like fungi have been identified based on some common anamorphic features such as their cultural morphology, colony colour, mycelial characteristics i.e. a slight constriction at branching point of the hypha, dolipore septa, nuclear number per cell, development of monilioid cells and sclerotia (Currah et al., 1987, 1988; Shan et al., 2002; Pereira et al., 2003; Zhu et al., 2008). The characteristics of the fungal endophyte isolated from G. calceolaris was, therefore, corroborated the identity with Rhizoctonia-like fungi belonging to the genus Ceratobasidium. Rhizoctonia-like fungi represent an assemblage of taxonomically diverse groups that differ in cultural and morphological features, including anamorph and teleomorph stages (Currah et al., 1987). The formation of asexual resistant propagules (monilioid cells), dolipore septum, constriction at branching point of the hypha, bi- or multinucleate vegetative and monilioid cells are the common anamorphic features of Rhizoctonialike fungi widely reported as orchid mycorrhizal fungi (Currah et al., 1997; Sneh et al., 1991; Otero et al., 2002; Shan et al., 2002). Nuclear number per cell varies from uni-, bi- to multinucleate in different orchid mycorrhizal fungi and even in different strains of the same species (Sneh et al., 1991; Otero et al., 2002; Pereira et al., 2014). This framework adopted by several researchers for identifying orchid mycorrhizal fungi offers a taxonomically correct and justified approach to define taxa (Shan et al., 2002). Sexual structures are generally more informative for taxonomy and systematics than the vegetative structures. However, fungi placed under the form-genus Rhizoctonia seldom reveal their basidiocarps, hence often referred to and identified by their anamorphs. Rhizoctonia-like fungi represent the genera Ceratorhiza, Epulorhiza, Monilioipsis, Rhizoctonia, Ceratobasidium, Thanatephorus, Tulasnella, and Sebacina (Warcup and Talbot, 1966). Species concepts within these genera can be corroborated based on finer culture characteristics such as mycelial morphology on specific media (Currah et al., 1990; Zelmer and Currah 1995; Andersen, 1996). 

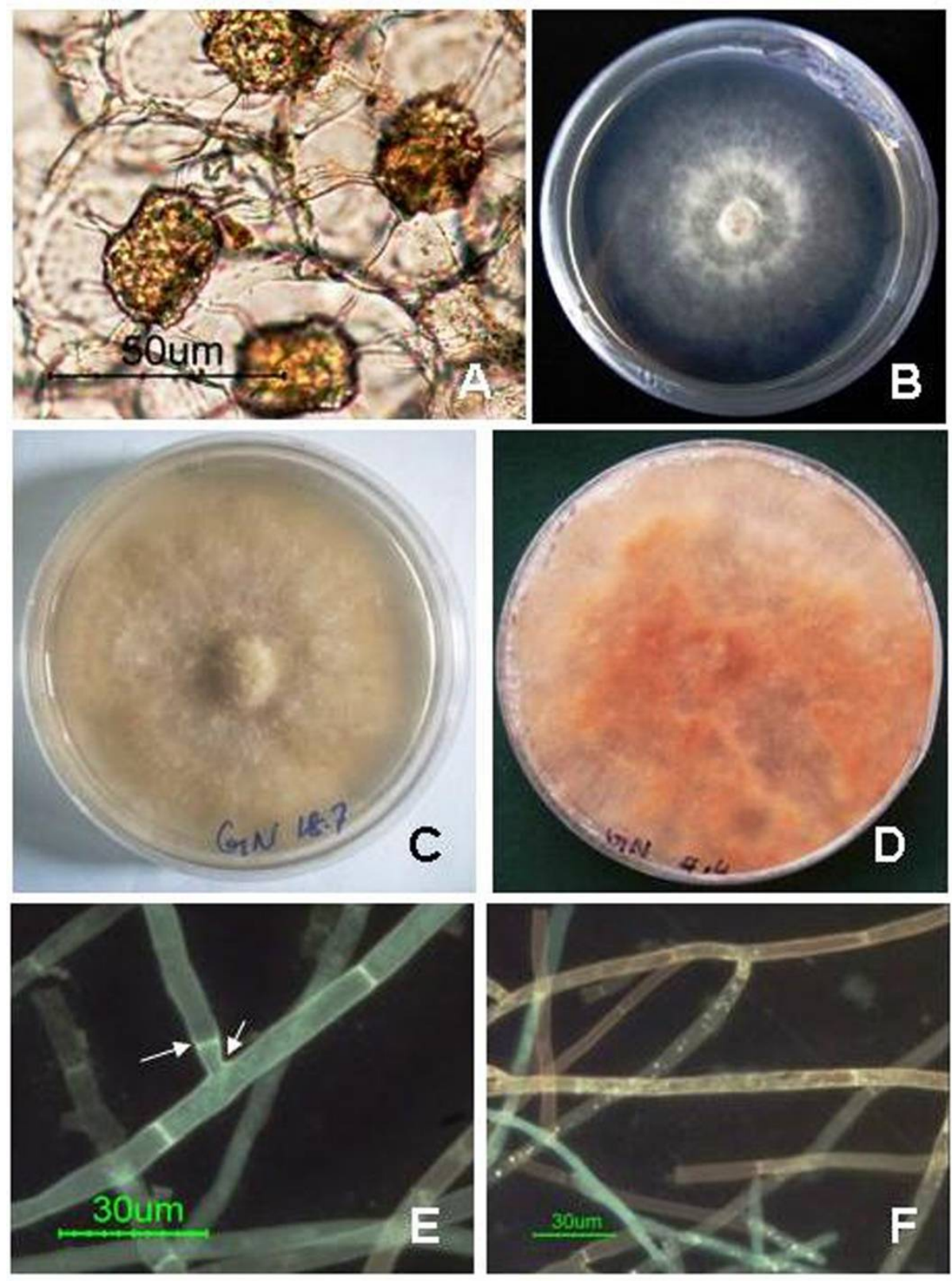

Fig. 1. A) Fungal pelotons in the T.S. of root of G. calceolaris, B) Five days old young colony of fungal endophyte on PDA surface, C-D) Fifteen days old mature colony front view and reverse view respectively, E) Fungal hyphae showing constriction and dolipore septum near the branching point (arrow), and F) Showing multinucleate vegetative cells after DAPI staining.

\section{Phylogenetic analysis}

The BLASTn search of ITS region sequences of nrDNA of the fungal isolates from $G$. calceolaris showed maximum identity with Ceratobasidium spp. reported as the widespread fungi developing mycorrhizal association with orchids (Otero et al., 2002). The phylogenetic tree was 
constructed based on the ITS region sequences of the fungal isolates and their closely related species formed distinct taxonomic group (Fig. 2). The ITS region sequences of Ceratobasidium sp. GC showed $98.28 \%$ similarity with Ceratobasidium sp. RR and $98.27 \%$ similarity with Ceratobasidium sp. FPUB 168, Rhizoctonia sp. M2ao1, Rhizoctonia sp. Abn1b and Rhizoctonia sp. Onv6. These fungi were isolated from Rhynchostylis retusa, Dactylorrhiza hatagirea, Aerides oradaia, Aranda Brite Ng, Oncidium varimyce $\times$ Oncidium nona, respectively (Ma et al., 2001; Otero et al., 2004; Aggarwal et al., 2007, Hossain et al., 2013). The ITS of nrDNA sequences data validated the morphological data and reconfirm the identity of the fungal endophyte isolated from G. calceolaris as Rhizoctonia-like fungi, Ceratobasidium sp.

Table 1. Morphological characteristics of Ceratobasidium sp. str. GC isolated from Gastrochilus calceolaris.

\begin{tabular}{ll}
\hline Parameter & Characteristics \\
\hline Colour of young colony (surface) & Cottony white \\
Colour of young colony (reverse) & Brownish white \\
Colour of mature colony (surface) & Light brown \\
Colour of mature colony (reverse) & Deep brown \\
Colony appearance & fluffy growth pattern \\
Colour of vegetative hyphae & Hyaline \\
Diameter of vegetative hyphae & $8-12 \mu \mathrm{m}$ \\
Shape of monilioid cells & Not found \\
Dimension of monilioid cells & - \\
Branching pattern & Right angle with slight constriction at the \\
Colony growth rate (mm/hr) & branching point \\
Nature of septum & $0.033-0.045$ \\
Spore & Dolipore septum \\
Nuclear condition in vegetative cell & Absent \\
\hline
\end{tabular}

The conventional approaches for identifying orchid mycorrhizal fungi have limitations as most of the fungal endophytes are mycelia sterilia. Consequently, the broad vegetative criteria for identification have resulted in paraphyletic taxonomy with various unrelated fungi being grouped together necessitating the application of molecular techniques for accurate identification (Otero et al., 2002; Shan et al., 2002; Dearnaley, 2007; Yagame et al., 2008). ITS region sequencing is the common and powerful molecular technique for accurate identification of orchid mycorrhizal fungi (Kuninaga et al., 1997; Taylor and Bruns, 1999; Salazar et al., 2000; Gonzalez et al., 2001; Pope and Carter, 2001; Sharon et al., 2008). The ITS region has several features that make it a strong candidate for a universal 'barcode' for fungal identification as it is easy to amplify due to high copy number and relatively few primer sets are needed as a result of the highly conserved SSU (small sub-unit) and LSU (large sub-unit) flanking regions, and varies relatively little within species but dramatically between species, and far better represented in GenBank than other loci in fungi (Taylor and McCormick, 2008; Zettler and Corey, 2018). The ITS region characterization of the endophytes isolated from G. calceolaris confirmed the identity with Ceratobasidium spp. 


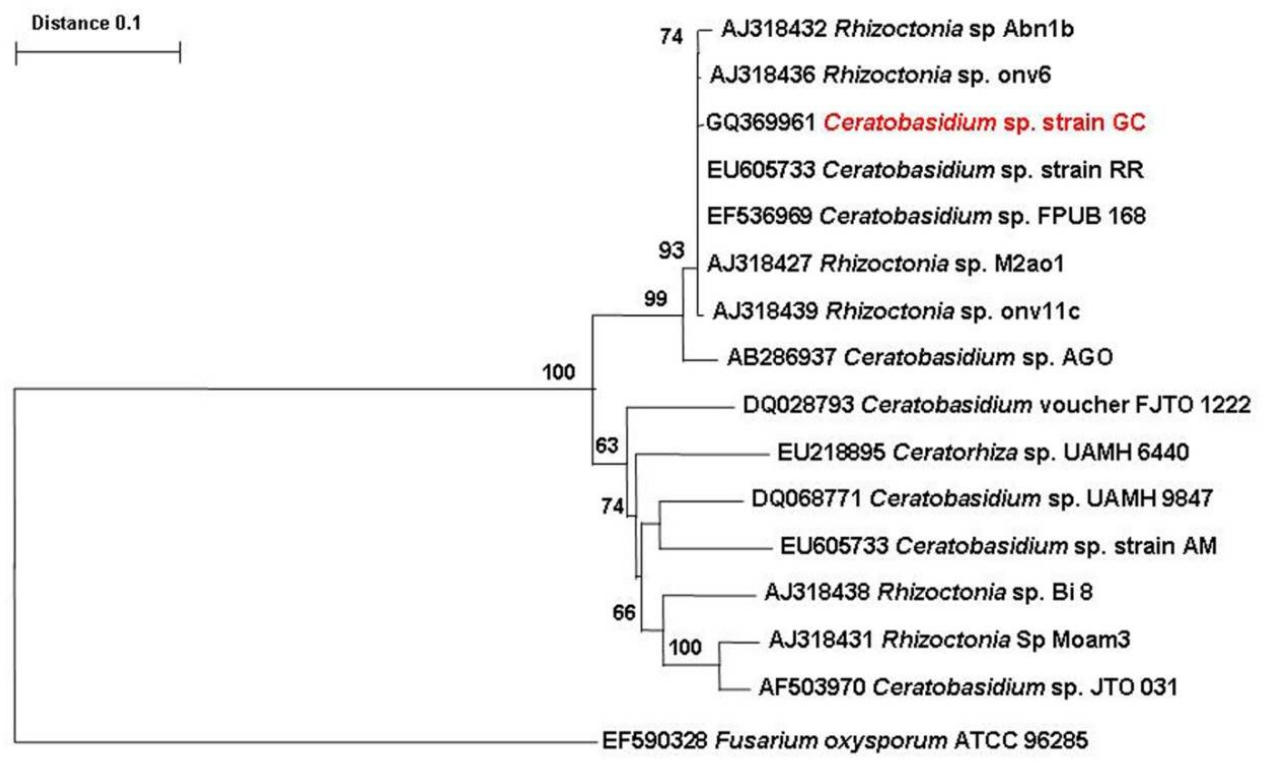

Fig. 2. Phylogenetic tree showing relationship among Ceratobasidium sp. strain GC and representatives of some related taxa based on ITS region analysis. Numbers on the nodes indicated bootstrap values. Fusarium oxysporum ATCC 96285 was used as the out-group. Bar, 0.1 substitution per site.

\section{Conclusion}

The mopho-molecular identification technique established for the root endophytic fungi Ceratobasidium sp. from G. calceolaris will help in easy and accurate identification of other orchid mycorrhizal fungi as well. This is also the first report on isolation, characterization and phylogentic analysis of orchid mycorrhiza from Bangladesh.

Conflict of interest: The author has no conflict of interest.

\section{References}

Aggarwal, S., Rahi, P., Gulati, A., Vij, S.P. and Dua, I.S. 2007. Symbiotic seed germination and development of seedling in Dactylorhiza hatagirea (D. Don) Soo - a critically endangered high value medicinal orchid. Fungal Diversity: Impact and Exploitation and $34^{\text {th }}$ Annual Meeting of Mycological Society of India, Department of Biotechnology and Environmental Sciences, Thapar University, Patiala, October 56, 2007.

Andersen, T.F. 1996. A comparative taxonomic study of Rhizoctonia sensu lato employing morphological, ultrastructural and molecular methods. Mycol. Res. 100: 1117-1128.

Andersen, T.F. and Staplers, J.A. 1994. A check-list of Rhizoctonia epithets. Mycotaxon 51: 437-457.

Bidartondo, M.I. 2005. The evolution of mycoheterotrophy. New Phytology 167: 335-352.

Burgeff, H. (1959). Mycorrhiza of Orchids. In: Withner CL (ed) The Orchids: a Scientific Survey. The Ronald Press Company, New York, pp 361-395.

Chang, D.C.N. 2007. The screening of orchid mycorrhizal fungi (OMF) and their applications. In: Chen WH \& Chen HH (eds) Orchid Biotechnology. World Scientific Publishing Co. Pvt. Ltd. Hong Kong, pp 77-98 
Currah, R.S., Hambleton, S. and Smreciu, A. 1988. Mycorrhizae and mycorrhizal fungi of Calypso bulbosa. American Journal of Botany 75:739-752.

Currah, R.S., Sigler, L. and Hambleton, S. 1987. New records and taxa of fungi from the mycorrhizae of terrestrial orchids of Alberta. Canadian Journal of Botany 65: 2473-2482.

Currah, R.S., Smreciu, E.A. and Hambleton, S. 1990. Mycorrhizae and mycorrhizal fungi of Plantanthera and Coeloglossum (Orchidaceae). Canadian Journal of Botany 68:1171-1181.

Currah, R.S., Zettler, L.W. and McInnis, T.M. 1997. Epulorhiza inquilina sp. nov. from Platanthera (Orchidaceae) and a key to Epulorhiza species. Mycotaxon 61: 335-342.

Dearnaley, J.D.W. 2007. Further advances in orchid mycorrhizal research. Mycorrhiza 17: 475-486

Gonzalez, D., Carling, D.E., Kuninaga, S., Vilgalys, R. and Cubeta, M. 2001. Ribosomal DNA systematics of Ceratobasidium and Thanatephorus with Rhizoctonia anamorphs. Mycologia 93:1138-1150

Hadley, G. 1982. Orchid mycorrhiza. In: Arditti J (ed.) Orchid biology: reviews and perspectives, vol II Cornell Univ Press, Ithaca. pp 83-118.

Hossain, M.M., Rahi, P., Gulati, A. and Sharma, M. 2013. Improved ex vitro survival of asymbiotically raised seedlings of Cymbidium using mycorrhizal fungi isolated from distant orchid taxa. Scientia Horticulturae 159: 109-116.

Julou, T., Burghardt, B., Gebauer, G., Berveiller, D., Damesin, C. and Selosse, M.A. 2005. Mixotrophy in orchids: insights from a comparative study of green individuals and nonphotosynthetic individuals of Cephalanthera damasonium. New Phytologist 166: 639-653.

Kimura, M. 1980. A simple method for estimating evolutionary rates of base substitutions through comparative studies of nucleotide sequences. Journal of Molecular Evolution 16: 111-120.

Kuninaga, S., Natsuaki, T., Takeuchi, T. and Yokosawa, R. 1997. Sequence variation of the rDNA ITS regions within and between anastomosis groups in Rhizoctonia solani. Current Genetics 32: 237-243.

Ma, M., Wong, J., Tan, T. and Wong, S. 2001. Molecular phylogeny of mycorrrhizal Rhizoctonia isolated from orchids in Singapore. Ph D thesis, National Uinversity of Singapore, Singapore.

Masuhara, G. and Katsuya, K. 1994. In situ and in vitro specificity between Rhizoctonia spp. and Spiranthes sinensis (Persoon) Ames. var. amoena (M.Bieberstein) Hara (Orchidaceae). New Phytologist 127: 711-718.

Otero, J.T., Ackerman, J.D. and Bayman, P. 2002. Diversity and host specificity of endophytic Rhizoctonialike fungi from tropical orchids. American Journal of Botany 89: 1852-1858.

Otero, J.T., Ackerman, J.D. and Bayman, P. 2004. Differences in mycorrhizal preferences between two tropical orchids. Molecular Ecology 13: 2393-2404.

Pereira, O.L., Rollemberg, C.L., Borges, A.C., Matsuoka, K. and Kasuya, C.M.M. 2003. Epulorhiza epiphytica sp. nov. isolated from mycorrhizal roots of epiphytic orchids in Brazil. Mycoscience 44: 153-155.

Pereira, M.C., da Silva, Coelho, I, da Silva. Valadares, R.B., Oliveira, S.F., Bocayuva, M., Pereira, O.L., Araújo, E.F. and Kasuya, M.C.M. 2014. Morphological and molecular characterization of Tulasnella spp. fungi isolated from the roots of Epidendrum secundum, a widespread Brazilian orchid. Symbiosis 62: 111-121.

Pope, E.J. and Carter, D.A. 2001. Phylogenetic placement and host specificity of mycorrhizal isolates AG-6 and AG-12 in the Rhizoctonia solani species complex. Mycologia 93: 712-719.

Ramsay, R.R., Sivasithamparam, K. and Dixon, K.W. 1987. Anastomosis groups among rhizoctonia-like endophytic fungi in southwestern Australian Pterostylis species (Orchidaceae). Lindleyana 2:161-166.

Salazar, O., Julian, M.C., Yacumachi, M. and Rubio, V. 2000. Phylogenetic grouping of cultural types of Rhizoctonia solani AG 2-2 based on ribosomal ITS sequences. Mycologia 92: 505-509.

Shan, X.C.E., Liew, C.Y., Weatherhead, M.A. and Hodgkiss, I.J. 2002. Characterization and taxonomic placement of Rhizoctonia-like endophytes from orchid roots. Mycologia 94: 230-239.

Sharon, M., Kuninaga, S., Hyakumachi, M., Naito, S. and Sneh, B. 2008. Classification of Rhizoctonia spp. using rDNA-ITS sequence analysis supports the genetic basis of the classical anastomosis grouping. Mycoscience 49: 93-114. 
Siddique, S. and Raghuvanshi, A. 1993. Seasonal changes in Vanda tessellata mycorrhizae. The Journal of the Orchid Society of India 7: 83-85.

Smith, S.E. and Read, D.J. 1997. Mycorrhizal symbiosis, 2nd edn. Academic, San Diego.

Sneh, B., Burpee, L. and Ogoshi, A.1991. Identification Of Rhizoctonia Species. American Phytopathological Society, St. Paul, Minnesota, USA.

Taylor, D.L. and McCormick. M.K. 2008. Internal transcribed spacer primers and sequences for improved characterization of basidiomycetous orchid mycorrhizas. New Phytologist 177:1020-1033.

Taylor, L.D. and Bruns, T.D. 1999. Population, habitat and genetic correlates of mycorrhizal specialization in the "cheating", orchids Corallorhiza maculata and C. mertensiana. Molecular Ecology 8:1719-1732.

Thakur, J., Dwivedi, M.D. and Uniyal, P.L. 2018. Ultrastructural studies and molecular characterization of root-associated fungi of Crepidium acuminatum (D. Don) Szlach.: a threatened and medicinally important taxon. Journal of Genetics 97: 1139-1146.

Thompson, J.D., Higgins, D.G. and Gibson, T.J. 1994. Clustal W: improving the sensitivity of progressive multiple sequence alignment through sequencing weighting,position sequence gap penalties and weight matrix choice. Nucleic Acids Research 22: 4673-4680.

Warcup, J.H. and Talbot, P.H.B. 1966. Perfect states of some Rhizoctonias. Transactions of the British Mycological Society 49: 427-435.

Yagame. T., Fukiharu, T., Yamato, M., Suzuki, A. and Iwase, K. 2008. Identification of a mycorrhizal fungus in Epipogium roseum (Orchidaceae) from morphological characteristics of basidiomata. Mycoscience 49:147-151.

Zelmer, C.D. and Currah, R.S. 1995. Ceratorhiza pernacatena and Epulorhiza calendulina spp. nov.: mycorrhizal fungi of terrestrial orchids. Canadian J. Bot. 73: 862-866.

Zettler, L.W. and Corey, L.L. 2018. Orchid Mycorrhizal Fungi: Isolation and Identification Techniques. In: Lee YI and Yeung ECT (eds.), Orchid Propagation: From Laboratories to Greenhouses-Methods and Protocols, Springer Protocols Handbooks, https://doi.org/10.1007/978-1-4939-7771-0_2.

Zhu, G.S., Yu, Z.N., Gui, Y. and Liu, Z.Y. 2008. A novel technique for isolating orchid mycorrhizal fungi. Fungal Diversity 33:123-137.

(Manuscript received on 10 May, 2019; revised on 10 December, 2019) 